\title{
PENGARUH MOTIVASI DAN DISIPLIN TERHADAP PRODUKTIVITAS KERJA KARYAWAN DI PT. RUBYCON INDONESIA
}

\author{
Resnawa Sitanggang, Riandani Rezki Prana, Dedi Wahyudi \\ Alumni Sekolah Tinggi Ilmu Manajemen Sukma \\ Program studi Manajemen, Sekolah Tinggi Ilmu Manajemen \\ Riandanirezki@gmail.com, dediw7084@gmail.com
}

\begin{abstract}
ABSTRAK
Kegiatan perusahaan yang bergerak dibidang industri perdagangan maupun jasa berusaha mencapai tujuan yang ditetapkan mencapai kesuksesan, dan saat ini sangat membutuhkan sumber daya manusia yang bisa berpikir maju, cerdas dan bersemangat untuk meningkatkan produktivitas kerja. Produktivitas kerja merupakan pencapaian hasil kerja karyawan dalam melaksanakan tugasyang diberikan perusahaan berdasarkan kemampuan, kesungguhan, serta waktu. Peningkatan produktivitas karyawan dalam suatu perusahaan sangat diperlukan agar tujuan utama perusahaan tercapai sesuai yang di inginkan dan produktivitas suatu perusahaan akan meningkat apabila terdapat kerjasama dan hubungan yang baik antara pemimpin dan karyawan. Untuk mendapatkan produktivitas kerja sesuai dengan ditetapkan mencapai tujuan optimal bukan hanya tergantung pada kemajuan teknologi dalam sarana dan prasarana yang dimiliki melainkan juga tergantung pada keryawan sebagai teman kerjasama. Karyawan yang memiliki motivasi akan mendorong rasa semangat diri sendiri mencapai tujuan lebih baik dari sebelumnya. Karyawan yang bermotivasi akan bertanggung jawab pada tugas yang diberikan, perusahaan akan memperoleh banyak keuntungan, pekerjaan lebih cepat diselesaikan, kerusakan dapat dikurangi, absen dapat diperkecil, produktivitas kerja dapat ditingkatkan. Disiplin juga dibutuhkan agar kegiatan perusahaan berjalan lancar, perusahaan juga berperan dalam mengelola karyawan agar memenuhi segala peraturan, norma yang telah ditetapkan sehingga para karyawan bekerja dengan disiplin dan efektif. Berusaha untuk selalu menekankan kepada sumber daya manusia untuk dapat mencapai produktivitas yang baik, akan bermanfaat untuk karyawan dan perusahaan.
\end{abstract}

\section{PENDAHULUAN}

Beberapa penelitian terdahulu menjelaskan bahwa motivasi dan disiplin berpengaruh terhadap produktifitas, sesuai dengan penelitian yang dilakukan oleh Yefrinaldi (2015) yang berjudul pengaruh motivasi kerja dan disiplin kerja terhadap produktivitas kerja pegawai Rumah sakit jiwa prof. Hb. Sa'anin padang menghasilkan motivasi kerja dan disiplin kerja berpengaruh signifikan terhadap produktivitas kerja pegawai pada Rumah Sakit Jiwa Prof. HB. Sa'anin Padang.

\section{Perumusan Masalah}

Berdasarkan uraian diatas, maka penulis merumuskan masalah penelitian ini sebagai berikut:

1. Apakah secara simultan ada pengaruh motivasi, disiplin terhadap produktifitas kerja karyawan di PT. Rubycon indonesia?

2. Apakah secara parsial ada pengaruh motivasi, disiplin terhadap produktivitas kerja karyawan di PT. Rubycon Indonesia? 


\section{Batasan Masalah}

Untuk memperjelas arah penelitian maka penelitian ini dibatasi hanya pada karyawan yang ada di bagian factory 9 .

\section{Tujuan Penelitian}

Adapun tujuan dalam penelitian ini adalah:

1. Untuk mengetahui secara simultan ada pengaruh motivasi, disiplin terhadap produktifitas kerja karyawan di PT. Rubycon indonesia.

2. Untuk mengetahui secara parsial ada pengaruh motivasi, disiplin terhadap produktivitas kerja karyawan di PT. Rubycon Indonesia.

\section{METODE PENELITIAN}

\section{Tempat dan Waktu Penelitian}

Penelitian ini dilakukan di PT. Rubycon Indonesia Lot 224, Jalan Gaharu, Batamindo Industrial Park, Muka Kuning yang akan dimulai pada bulan Agustustus sampai dengan Oktober 20016.

\section{Jenis dan Sumber data}

a. Data primer adalah sumber data yang diperoleh dari hasil penelitian langsung dari lapangan, data-data tersebut seperti jawaban responden tentang produktivitas tenaga kerja dari pengaruh motivasi dan disiplin.

b. Data skunder adalah data yang diperoleh dari hasil laporan pihak terkait seperti jumlah karyawan, jumlah produktivitas atau output dan lain-lain.

\section{Populasi Dan Sampel}

Dalam penelitian ini, penulis mengambil sample pada factory 9 yang merupakan langkah awal dalam memproses produksi product. Jumlah karyawan factory 9 adalah 60 karyawan didalamnya termasuk supervisor, leader, karyawan.

\section{Defenisi Operasional Variabel}

Berdasarkan rumusan masalah, maka variabel-variabel dalam penelitian ini dapat diidentifikasi sebagai berikut:

1. Variabel bebas (variabel independen) adalah variabel yang mempengaruhi variabel terikat, yang terdiri dari motivasi $\left(\mathrm{X}_{1}\right)$ dan disiplin $\left(\mathrm{X}_{2}\right)$;

2. Variabel terikat (variabel dependen) adalah variabel yang dipengaruhi oleh variabel bebas, yaitu produktivitas kerja (Y).

Tabel 1.Operasionalisasi Variabel Penelitian

\begin{tabular}{|l|l|l|l|l|}
\hline & $\begin{array}{l}\text { Variabe } \\
\text { I }\end{array}$ & Defenisi Operasional & Indikator & $\begin{array}{l}\text { Skala } \\
\text { Ukur }\end{array}$ \\
\hline $\begin{array}{l}\text { Motivas } \\
\text { i }\left(\mathrm{X}_{1}\right)\end{array}$ & $\begin{array}{l}\text { Motivasi kerja adalah hasil dari } \\
\text { kumpulan kekuatan internal dan } \\
\text { eksternal yang menyebabkan } \\
\text { pekerja memilih jalan bertindak } \\
\text { yang sesuai da menggunakan } \\
\text { perilaku tertentu. }\end{array}$ & $\begin{array}{l}\text { a. Engament } \\
\text { c. Satistaction } \\
\text { d. Turnover }\end{array}$ & Likert \\
\hline $\begin{array}{l}\text { Disiplin } \\
\left(\mathrm{X}_{2}\right)\end{array}$ & $\begin{array}{l}\text { Kedisiplinan adalah kesadaran dan } \\
\text { kesediaan seseorang mentaati } \\
\text { semua peraturan-perturan } \\
\text { perusahaan dan norma-norma yang }\end{array}$ & $\begin{array}{l}\text { a. Tujuan dan } \\
\text { kemampuan } \\
\text { b. Teladan pimpinan } \\
\text { c. Balas jasa }\end{array}$ & Likert \\
\hline
\end{tabular}




\begin{tabular}{|c|c|c|c|}
\hline & berlaku & $\begin{array}{l}\text { d. Keadilan } \\
\text { e. Waskat } \\
\text { f. Sanksi hukuman } \\
\text { 7. Ketegasan } \\
8 \quad \text {.Hubungan } \\
\text { kemanusiaan }\end{array}$ & \\
\hline $\begin{array}{l}\text { Produkti } \\
\text { vitas }(Y)\end{array}$ & $\begin{array}{l}\text { Produktivitas adalah ukuran } \\
\text { efisiensi produktif }\end{array}$ & $\begin{array}{l}\text { a. Kemampuan } \\
\text { b.Meningkatkan hasil } \\
\text { yang dicapai } \\
\text { c. Semangat kerja } \\
\text { d. Pengembangan diri } \\
\text { e. Mutu } \\
\text { f. Efisiensi }\end{array}$ & Likert \\
\hline
\end{tabular}

\section{Metode Pengumpulan Data}

a. Kusioner yaitu metode pengumpulan data dengan membuat daftar pertanyaan yang diajukan kepada karyawaan (responden) sebagai contoh dari penelitian ini.

b. Observasi yaitu mengadakan tinjauan langsung dengan melihat bentuk motivasi dan disiplin yang diberikan serta ditetapkan kepada karyawan PT. Rubycon Indonesia. Metode ini digunakan dengan tujuan untuk memperoleh data primer dan skunder

\section{Kerangka Berpikir}

Penelitian ini bersifat kuantitatif karena menggunakan data yang memerlukan perhitungan dan menggunakan analisa kuantitatif untuk mendiskripsikan data-data yang sudah diperoleh sehingga akan lebih jelas data tersebut. Pada penelitian ini terdapat variabel $\mathrm{X}_{1}$ (motivasi) dan $\mathrm{X}_{2}$ (disiplin) sebagai independen dan variabel $\mathrm{Y}$ (produktivitas) sebagai dependen.

\section{Metode Analisis Data}

a. Uji Validitas digunakan untuk mengukur valid dan tidak validnya suatu kuesioner. Kuesioner valid jika kuesioner mampu mengungkapkan sesuatu yang diukur oleh kuesioner tersebut

b. Uji Reabilitas adalah alat untuk mengukur suatu kuesioner yang merupakan indikator variabel atau konstruk. Kuesioner dikatakan reliabel konsisten. Dalam penelitian ini untuk menentukan kousioner reliabel atau tidak reliabel menggunakan alpha cronbach.

c. Analisis regresi linear berganda adalah alat analisis yang dipergunakan untuk mengukur pengaruh dua atau lebih variabel bebas terhadap variabel terikat. Dengan rumus sebagai berikut: $\mathbf{Y}=\mathbf{a}+\mathbf{b}_{1} \mathbf{X}_{\mathbf{1}}+\mathbf{b}_{2} \mathbf{X}_{2}+\mathbf{e}$

Keterangan:

$\mathrm{Y}=$ Variabel terikat (produktivitas kerja)

a $\quad=$ konstanta

$\mathrm{b}_{1} \mathrm{~b}_{2} \quad=$ koefisien regrasi berganda

$\mathrm{X}_{1} \quad=$ Motivasi kerja

$\mathrm{X}_{2} \quad=$ Disiplin kerja

e $\quad=$ Standart error 


\section{Pengujian Hipotesis}

a. Uji Simultan (Uji F)

Penggunaan uji ini dimaksudkan untuk menyelidiki kesesuaian datadengan model, dengan itu dapat diketahui motivasi disiplin secara simultan terhadap produktivitas. Dan dapat dilihat dari tingkat kebenaran 95\% atau tingkat kesalahan $\alpha=0,05(5 \%)$, dengan asumsi:

1. Jika $\mathrm{F}_{\text {hitung }} \leq \mathrm{F}$ tabel, maka $\mathrm{H}_{0}$ diterima, $\mathrm{H}_{1}$ ditolak, artinya secara simultan penelitian tidak ada pengaruh;

2. Jika $\mathrm{F}_{\text {hitung }}>\mathrm{F}$ tabel, maka $\mathrm{H}_{0}$ ditolak, $\mathrm{H}_{1}$ diterima, artinya secara simultan penelitian terdapat pengaruh (berpengaruh).

b. Uji Parsial (Uji T)

Uji parsial bertujuan untuk melihat pengaruh motivasi dan disiplin terhadap produktivitas kerja, dengan asumsi:

1. Jika $\mathrm{t}_{\text {hitun }} \leq \mathrm{t}_{\text {tabel }}$ maka $\mathrm{H}_{0}$ diterima, $\mathrm{H}_{1}$ ditolak, artinya secara parsial penelitian tidak ada pengaruh:

2. Jika $t_{\text {hitung }}>t_{\text {tabel }}$ maka $\mathrm{H}_{0}$ ditolak, $\mathrm{H}_{1}$ diterima, artinya secara parsial penelitian terdapat pengaruh (berpengaruh)

c. Koefisien Determinasi $\left(\mathrm{R}^{2}\right)$

$\mathrm{R}^{2}$ adalah perbandingan antara variasi (kinerja) yang dijelaskan oleh motivasi, disiplin, secara bersama-sama dibandingkan dengan variasi total kerja. Semakin besar nilai koefisien determinasi (mendekati satu)maka dapat disimpulkan bahwa pengaruh variabel bebas $\left(\mathrm{X}_{1}\right.$ dan $\left.\mathrm{X}_{2}\right)$ adalah besar terhadap variabel terikat $(\mathrm{Y})$

\section{HASIL PENELITIAN DAN PEMBAHASAN}

\section{Hasil Penelitian}

\section{Uji validitas}

Pengujian instrumen penelitian baik dilihat dari segi validitasnya maupun realibilitas terhadap 60 responden diperoleh bahwa hasil instrumen penelitian yang dipergunakan adalah valid dimana nilai korelasi produc momen pearson dengan level signifikan 5\% adalah lebih besar 0.3 . Sedangkan untuk uji reabilitasnya digunakan dengan metode alpha cronbach $(\alpha)$ lebih besar dari 0.60 dapat dinyatakan bahwa instrumen yang diguanakan adalah reliabel.

\section{Uji Reliabilitas}

Rekapitulasi hasil uji validitas dan realibilitas dari setiap pertanyaan dapat dilihat pada tabel berikut:

Tabel 2. Uji Validitas dan Realibilitas

\begin{tabular}{|l|l|l|l|l|l|}
\hline Variabel & Item & $\begin{array}{l}\text { Koefesien } \\
\text { Korelasi }\end{array}$ & Keputusan Valid & $\begin{array}{l}\text { Koefesiem } \\
\text { Alpha }\end{array}$ & $\begin{array}{l}\text { Keputusan } \\
\text { Realiabel }\end{array}$ \\
\hline \multirow{4}{*}{ X1 } & P-1 & 0.678 & Valid & & \multirow{3}{*}{0.812} \\
\cline { 2 - 4 } & P-2 & 0.627 & Valid & & \\
\cline { 2 - 4 } & P-3 & 0.620 & Valid & & \\
\cline { 2 - 4 } & P-4 & 0.667 & Valid & & \\
\cline { 2 - 4 } & & & & & \\
\hline \multirow{5}{*}{} & P-1 & 0.547 & Valid & \\
\cline { 2 - 4 } & P-2 & 0.652 & Valid & & \\
\cline { 2 - 4 } & P-3 & 0.674 & Valid & & \\
\cline { 2 - 4 } & P-4 & 0.576 & Valid & & \\
\hline
\end{tabular}




\begin{tabular}{|l|l|l|l|l|l|}
\hline X2 & P-5 & 0.681 & Valid & \multirow{2}{*}{0.865} & Realiabel \\
\cline { 2 - 4 } & P-6 & 0.658 & Valid & & \\
\cline { 2 - 4 } & P-7 & 0.598 & Valid & & \\
\cline { 2 - 4 } & P-8 & 0.566 & Valid & & \\
\hline \multirow{4}{*}{ Y } & P-1 & 0.809 & Valid & & \\
\cline { 2 - 4 } & P-2 & 0.790 & Valid & & \multirow{3}{*}{ Realiabel } \\
\cline { 2 - 4 } & P-3 & 0.602 & Valid & & \\
\cline { 2 - 4 } & P-4 & 0.642 & Valid & & \\
\cline { 2 - 4 } & P-5 & 0.562 & Valid & & \\
\cline { 2 - 4 } & P-6 & 0.499 & Valid & & \\
\hline
\end{tabular}

Berdasarkan hasil uji validitas dan realibilitas yang dilakukan terhadap tiap item instrumen yang digunakan dalam penelitian dapat dikatakan valid dan realiabel karena telah memenuhi kriteria pengujian, baik validitas maupun realibilitas, yaitu untuk variabel (X1) motivasi sebesar 0.821, variabel (X2) disiplin sebesar 0.852 dan variabel (Y) produktivitas sebesar 0.823 .

\section{Uji Regresi Linear Berganda}

Uji regresi linear berganda dilakukan dengan bantuan IMB SPSS Statistics 20 dengan tujuan untuk mengetahui seberapa besar pengaruh variabel bebas yang terdiri dari motivasi (X1), Disiplin (X2) terhadap produktivitas (Y) sebagai variabel terikat. Persamaan regresi linear berganda yang digunakan adalah $Y=a+b_{1} X_{1}+b_{2} X_{2}+e$

Tabel 3. Hasil Uji Regresi Linear Berganda Olahan SPSS version 20 Coefficients $^{\mathrm{a}}$

\begin{tabular}{|cc|c|c|c|c|c|}
\hline \multirow{2}{*}{ Model } & \multicolumn{2}{|c|}{$\begin{array}{c}\text { Unstandardized } \\
\text { Coefficients }\end{array}$} & $\begin{array}{c}\text { Standardized } \\
\text { Coefficients }\end{array}$ & \multirow{2}{*}{ Sig. } & \\
\cline { 3 - 5 } & & $\mathrm{B}$ & Std. Error & Beta & & \\
\hline \multirow{2}{*}{1} & (Constant) & 6.778 & 3.016 & & 2.247 & .029 \\
& $\mathrm{X} 1$ & .327 & .154 & .264 & 2.123 & .038 \\
& $\mathrm{X} 2$ & .379 & .103 & .456 & 3.670 & .001 \\
\hline
\end{tabular}

a. Dependent Variable: Y

$\mathrm{Y}=6.778+0.327 \mathrm{X}_{1}+0.379 \mathrm{X}_{2}+\mathrm{e}$

Berdasarkan persamaan diatas maka dapat diuraikan sebagai berikut:

1. Interpretasi dari persamaan regresi linier berganda, yakni:

a. Jika segala sesuatu pada variabel-variabel independen dianggap konstan maka produktivitas sebesar 6.778

b. Jika terjadi penambahan kenaikan tingkat motivasi kerja sebesar 1 satuan, maka produktivitas akan naik sebesar 0.327

c. Jika terjadi penambahan atau kenaikan disiplin kerja 1 satuan. Maka produktivitas kerja akan naik sebesar 0.379

2. Motivasi kerja berpengaruh positif terhadap produktivitas dengan koefisien regresi sebesar 0.327 tanda + positif pada variabel motivasi menunjukkan hubungan yang searah, artinya bila usaha memotivasi karyawan ditingkatkan maka akan berpengaruh terhadap meningkatnya produktivitas.

3. Disiplin berpengaruh positif terhadap produktivitas kerja karyawan dengan koefisien regresi sebesar 0.379 tanda + (positif) pada variabel kedisiplinan kerja karyawan menunjukkan hubungan yang searah, artinya bila disiplin ditingkatkan maka akan berpengaruh terhadap meningkatnya produktivitas kerja karyawan. 


\section{Uji Hipotesis}

a. Uji Signifikan Simultan (Uji-F)

Pengujian ini dilakukan untuk melihat apakah semua variabel bebas yang dimasukkan dalam model mempunyai pengaruh secara bersama-sama terhadap variabel terikat. Kriteria pengujian ini adalah:

1. $\mathrm{H}_{0}: \mathrm{b}_{1}, \mathrm{~b}_{2}=0$ artinya secara serentak tidak terdapat pengaruh positif dan signifikan dari variabel bebas terhadap variabel terikat

2. $\mathrm{H}_{0}: \mathrm{b}_{1}: \mathrm{b}_{2 \neq} 0$ artinya secara serentak terdapat pengaruh positif dan signifikan dari variabel bebas terhadap variabel terikat.

$$
\begin{aligned}
& \mathrm{d}_{\mathrm{f}}:(\text { pembilang })=\mathrm{k}-\mathrm{I} \\
& \mathrm{d}_{\mathrm{f}}:(\text { penyebut })=\mathrm{n}-\mathrm{k}
\end{aligned}
$$

keterangan:

$$
\begin{aligned}
& \mathrm{n}=\text { jumlah sampel penelitian } \\
& \mathrm{k}=\text { jumlah variabel bebas dan terikat }
\end{aligned}
$$

pada penelitian ini diketahui jumlah sampel (n) 52 dan jumlah kesuluruahan variabel (k) 3 , sehingga diperoleh:

1. df1 (pembilang) $=3-1=2$

2. $\mathrm{df} 2$ (penyebut) $=60-2=58$

Nilai f hitung akan diperoleh dengan menggunakan bantuan IBM SPSS version 20 kemudian akan dibandingkan dengan $\mathrm{f}$ tabel pada tingkat $\alpha=5 \%$ atau 0.05 , dengan rumus tersebut maka nilai $\mathrm{f}$ tabel adalah 3.16.

Tabel 4. Hasil Uji F Olahan SPSS Version 20

\section{ANOVA $^{\mathrm{a}}$}

\begin{tabular}{|ll|l|l|l|l|l|}
\hline \multicolumn{2}{|c|}{} & Sum of Squares & Df & Mean Square & F & Sig. \\
\hline \multirow{2}{*}{1} & Regression & 149.348 & 2 & 374.674 & 20.524 & $.000^{\text {a }}$ \\
& Residual & 207,386 & 57 & 3.638 & & \\
& Total & 356.733 & 59 & & & \\
\hline
\end{tabular}

a. Dependent Variable: Y

b. Predictors: (Constant), X2, X1

Hasil uji F dapat dilihat pada tabel diatas:

1. Hasil pengujian ANOVA dengan menggunakan uji $F$ pada tabel diatas memperlihatkan nilai $\mathrm{F}$ hitung sebesar 20.524 dengan signifikansi $0,000^{\mathrm{a}}$. Dengan mencari $\mathrm{F}$ tabel, dengan $\mathrm{df} 1=2$ dan $\mathrm{df} 2=57$, diperoleh $\mathrm{F}$ tabel 3.16. Dengan kondisi dimana F hitung lebih besar dari f tabel(20.524> 3.16) dengan nilai Sig yang lebih kecil dari alpha $(0,000<0.05)$, maka kesimpulan dapat diambil adalah $\mathrm{H}_{0}$ yang berarti koefisien korelasi signifikan secara statistik motivasi dan disiplin secara bersamasama berpengaruh terhadap produktivitas karyawan.

2. Kolom pertama uji ANOVA yaitu kolom regresi adalah jumlah kuadrat dari varians yang dihasilkan oleh mode persamaan regresi yaitu sebesar 149.348, sedangkan kolom kedua yaitu residual adalah jumlah kuadrat varians yang tidak dihasilkan dari model persamaan regresi yaitu sebesar 207.386

c. Uji Parsial (Uji T)

Uji t menunjukkan seberapa besar pengaruh variabel secara individual terhadap variabel terikat $\mathrm{H}_{0}: \mathrm{b}_{1}=0$, artinaya parsial tidak terdapat pengaruh yang positif dan signifikan dari variabel bebas $\left(\mathrm{X}_{1}, \mathrm{X}_{2}\right)$ yaitu berupa motivasi dan disiplin terhadap produktivitas kerja karyawan yang ditulis sebagai variabel terikat $(\mathrm{Y}) . \mathrm{H}_{0}: \mathrm{b}_{1} \neq 0$ artinya parsial terdapat pengaruh yang positif dan signifikan dari variabel bebas $\left(\mathrm{X}_{1}\right.$ dan $\left.\mathrm{X}_{2}\right)$ yaitu berupa motivasi dan disiplin terhadap produktivitas kerja karyawan yang ditulis sebagai variabel terikat (Y). 
Tabel 5. Hasil Uji T Olahan SPSS Version 20

\begin{tabular}{|ll|l|l|l|l|l|}
\hline \multirow{2}{*}{ Model } & \multicolumn{2}{|l|}{ Unstandardized Coefficients } & $\begin{array}{l}\text { Standardized } \\
\text { Coefficients }\end{array}$ & & \multirow{2}{*}{ Sig. } \\
\cline { 2 - 5 } & & B & Std. Error & Beta & & \\
\hline \multirow{2}{*}{1} & (Constant) & 6.778 & 3.016 & & 2.247 & .029 \\
& X1 & .327 & .154 & .264 & 2.123 & .038 \\
& X2 & .379 & .103 & .456 & 3.670 & .001 \\
\hline
\end{tabular}

Berdasarkan tabel 5. dapat disimpulkan sebagai sebagai berikut:

1. Motivasi kerja $\left(\mathrm{X}_{1}\right)$ berpengaruh secara positif dan signifikan terhadap produktivitas kerja karyawan, hal ini terlihat dari nilai signifikan 0.038 lebih kecil dari 0.05 . Nilai $\mathrm{t}_{\text {hitung }} 2.123<\mathrm{t}_{\text {tabel }} 20.524$ artinya jika ditingkatkan variabel motivasi sebesar satu satuan maka produktivitas kerja karyawan (Y) akan meningkat sebesar satu satuan.

2. Disiplin $\left(\mathrm{X}_{2}\right)$ berpengaruh secara positif dan signifikan terhadap produktivitas kerja karyawan. Hal ini terlihat dari nilai signifikan lebih kecil 0.04 dari 0,05 . Nilai $t_{\text {hitung }}$ $3.670>\mathrm{t}_{\text {tabel }} 20.524$ artinay jika ditingkatkan variabel disiplin kerja sebesar satu satuan maka produktivitas karyawan (Y) meningkat sebesar 0.379 satuan.

3. Konstanta sebesar 6.778, artinya walaupun variabel bebas bernilai nol maka produktivitas kerja karyawan tetap sebesar 6.778 .

4. Berdasarkan hasil uji t maka rumus persamaan regresinya adalah

$\mathrm{Y}=\mathrm{a}+\mathrm{b}_{1} \mathrm{X}_{1}+\mathrm{b}_{2} \mathrm{X}_{2}+\mathrm{e}$

$\mathrm{Y}=6.778+0.327 \mathrm{X}_{1}+0.379 \mathrm{X}_{2}$

d. Koefisien Determinasi $\left(\mathrm{R}^{2}\right)$

Koefisien determinan digunakan untuk mengukur seberapa besar kontribusi variabel bebas (motivasi dan disiplin) terhadap variabel terikat (produktivitas). Koefisien determinasi berkisar nol sampai satu $\left(0 \leq \mathrm{R}^{2} \geq 1\right)$. Jika $\mathrm{R}^{2}$ semakin besar (mendekati satu), maka dapat dikatakan bahwa pengaruh variabel bebas $\left(\mathrm{X}_{1}\right)$ yaitu motivasi, $\left(\mathrm{X}_{2}\right)$ disiplin adalah besar terhadap variabel terikat $(\mathrm{Y})$ yaitu produktivitas kerja karyawan. Hal ini berarti model yang digunakan semakin kuat untuk menerangkan pengaruh variabel bebas terhadap variabel terikat dan demikian sebaliknya.

Tabel 6. Hasil Uji R ${ }^{2}$ Hasil Olahan SPSS Version 20

Model Summary ${ }^{\mathrm{b}}$

\begin{tabular}{|l|l|l|l|l|l|}
\hline Model & $\mathrm{R}$ & R Square & $\begin{array}{l}\text { Adjusted } \\
\text { Square }\end{array}$ & $\begin{array}{l}\text { Rtd. Error of the } \\
\text { Estimate }\end{array}$ & \\
\hline 1 & $.647^{\mathrm{a}}$ & .419 & .398 & .1907 & \\
\hline
\end{tabular}

a. Predictors: (Constant), X2, X1

b. Dependent Variable: Y

Berdasarkan tabel 4.5.c dapat diuraikan sebagai berikut:

1. Nilai $R$ sebesar 0.647 , berarti hubungan anatara motivasi $\left(X_{1}\right)$ dan disiplin $\left(X_{2}\right)$ terhadap variabel produktivitas kerja karyawan (Y), pada PT.Rubycon Indonesia 64,7 $\%$ artinya hubungan cukup erat.

2. Adjusted $R$ square sebesar 0.398 , berarti $39,8 \%$ berarti variabel produktivitas dapat dijelaskan oleh variabel motivasi dan disiplin sedangkan sisanya $70,2 \%$ dapat 
dijelaskan variabel lain yang tidak diteliti dalam penelitian ini seperti intensif, promosi, kepuasan kerja, prestasi kerja dan lainnya.

\section{Pembahasan}

Pengararuh Motivasi Terhadap Produktivitas Kerja Karyawan pada PT. Rubycon Indonesia Berdasarkan hasil penelitian menunjukkan bahwa motivasiberpengaruh positif terhadap produktivitas kerja karyawan pada PT. Rubycon Indonesia. Hasil penelitian menunjukkan bahwa motivasi berpengaruh signifikan terhadap produktivitas kerja karyawan. Pada dasarnya motivasi adalah dorongan rasa semangat yang timbul dari diri sendiri untuk mencapai keinginannya.Hasil penelitian sejalan dengan penelitian terdahulu yang dilakukan oleh Yefrinaldi (2015) yang berjudul "Pengaruh Motivasi dan Disiplin KerjaTerhadap Produktivitas Kerja pegawai Rumah Sakit Jiwa Prof. HB. Sa'anin Padang, berpengaruh positif dan signifikan".

Pengaruh Disiplin Terhadap Produktivitas Kerja Karyawan pada PT. Rubycon Indonesia. Penelitian menunjukkan bahwa disiplin kerja berpengaruh positif dan signifikan terhadap Produktivitas Kerja Karyawan PT. Rubycon Indonesia. Melalui disiplin yang tinggi, produktivitas kerja karyawan dapat ditingkatkan oleh sebab itu perlu ditanamkan kepada setiap karyawan disiplin yang sebaik-baiknya. Hasil penelitian ini juga didukungdan sejalan dengan penelitian terdahulu yang dilakukan Yefrinaldi (2015) melakukan penelitian yang berjudul "Pengaruh Disiplin Terhadap produktivitas kerja pegawai Rumah Sakit Jiwa Prof. HB. Sa'anin padang". Hasil penelitian ini menunjukkan bahwa variabel Disiplin (X2) berpengaruh positif dan signifikan terhadap produktivitas kerja karyawan (Y), artinya semakin baik motivasi dan disiplin karyawan, maka produktivitas kerja juga semakin tinggi.

\section{KESIMPULAN}

Berdasarkan hasil penelitian dan pembahasan pada bab sebelumnya, maka dapat disimpulkan:

1. Hasil penelitian ini menunjukkan bahwa variabel motivasi dan disiplin secara simultan berpengaruh positif dan signifikan terhadap produktivitas kerja karyawan PT. Rubycon Indonesia.

2. Berdasarkan hasil uji t secara parsial yang dominan mempengaruhi produktivitas kerja karyawan PT. Rubycon Indonesia adalah variabel disiplin, sedangkan motivasi berpengaruh positif dandominan mempengaruhi produktivitas kerja.

3. Dari hasil analisis koefisien determinasi diperoleh nilai R AdjustedSquare(R2) sebesar 0.398 hal ini berarti 39,8\% variabel produktivitas dapat dijelaskan oleh variabel motivasi kerja dan variabel disiplin kerja, sedangkan sisanya sebesar $70.2 \%$ dapat dijelaskan oleh variabel lainyang tidak diteliti dalam penelitian ini. 


\section{REFERENCES}

Badriyah, M. (2015).ManajemenSumberDayaManusia (1st ed.). Bandung: CV. PustakaSetia.

Dinamika, S. G., \& Sari, W. V. (2015). Applied Error Analysis of Comparative Degree Sentence Construction of Students in STIM Sukma Medan. Asian EFL Journal, 5, $112-119$.

Dinamika, S. G., \& Siregar, E. B. A. (2016). Developing English Syllabus for Tourism Management Students. In Proceedings of the Fourth International Seminar on English Language and Teaching (ISELT-4) (Vol. 13, pp. 16-17).

Dinamika, Soraya Grabiella (2014) THE EFFECT OF USING COLLABORATIVE STRATEGIC READING ON STUDENTS' ACHIEVEMENT IN READING NARRATIVE TEXT. Undergraduate thesis, UNIMED

Fathimah, V. (2017). Pengaruh Perkembangan Jumlah Tabungan, Deposito dan Bagi Hasil terhadap Jumlah Pembiayaan yang Diberikan oleh Perbankan Syariah di Sumatera Utara. Jurnal Ilman, 5(1), 41-52.

Hasibuan, M. S. P. (2013). ManajemenSumberDayaManusia (RevisiCet). Jakarta: BumiAksara.

Hidayat, R. (2010). Analisis Tingkat Penggunaan Internet Dikalangan Mahasiswa dan Hubungannya dalam Peningkatan Nilai Akademik (Studi Kasus pada Mahasiswa di Kota Medan). Jurnal Mediasi, 2(2), 55-63.

Hidayat, R. (2015). Performance Appraisal sebagai Alat Pengukuran Kepuasan Kerja Karyawan. Jurnal Ilman, 3(1), 1-8.

Mangkunegara, A. A. A. P. (2013). ManajemenSumberDayaManusia (11th ed.). Bandung: PT. RemajaRosdakarya.

Nasution, W. A. (2009). Pengaruh kepuasan kerja karyawan terhadap intensi turnover pada call center Telkomsel di Medan. Jurnal Mandiri, 4(1), 1-11.

Nasutiona, L. K., Fahrurb, M., Christine, Imaduddind, \& Wardayani. (2017). The Calculation of Cost of Goods Sold "Gayo Arabica Coffee from Takengon" with Variable Costing Method. Journal Online Jaringan COT POLIPD (JOJAPS), 10, $82-87$.

Ningratri, Y. A. (2017). Analisis Pengaruh Strategi Bauran Pemasaran Jasa (3P) terhadap Keputusan Mahasiswa Memilih STIM Sukma Medan. Riset \& Ejurnal Manajemen Informatika, 3(1), 50-56.

Nurlinda, \& Wardayani. (2014). Pengaruh Partisipasi Penyusunan Anggaran Dan Penggunaan Instrumen Manajemen Terhadap Kinerja Pengelolaan Dana Bantuan Global Fund Komponen Aids Pada Kementerian Kesehatan Ri. Jurnal Ilman, 1(1), $23-35$. 
Prana, R. R. (2016). Analisis Faktor-faktor yang Mempengaruhi Pendapatan Asli Daerah (PAD) Kota Tebing Tinggi. Jurnal Ilman, 4(1), 74-86.

Sinaga, S., Pertiwi, L. S., Ardian, T., \& Zuhri. (2016). Inventory Simulation Optimization Under Non Stationary Demand. International Journal of Applied Engineering Research, 11(1), 524-529.

Sinuhaji, E. (2010). PENERAPAN LAYANAN UNGGUL DALAM PEMASARAN PRODUK BANK. Jurnal Mediasi, 2(1).

Sinuhaji, E. (2014). Pengaruh Kepribadian, Kemampuan Kerja dan Motivasi Kerja terhadap Kinerja SDM Outsourcing pada PT. Catur Karya Sentosa Medan. Jurnal Ilman, $1(1), 11-22$.

Strom, N. (2011). PerilakuDalamOrganisasi. Jakarta: Rajawali Pers.

Sukendro, H. A. (2012). Pengaruh Citra Merek dan Kualitas Pelayanan terhadap Kepuasan Jama'ah pada Kelompok Bimbingan Ibadah Haji (KBIH) Indosat Medan. Universitas Terbuka.

Sunyoto, D. (2013). TeoriAnalisisPerilakuOrganisasi. Jogjakarta: Apssed.

Sutrisno, E. (2014). ManajemenSumberDayaManusia (6th ed.). jakarta: Prenadamedia Group.

Widjanarko, B. (2015). PENGARUH PEMERIAN KOMPENSASI DAN KOMUNIKASI TERHADAP SEMANGAT KERJA KARYAWAN PADA BUMI KARYA TAMA INSURANCE CABANG MEDAN. Jurnal Research Sains, 1(2), 130152.

Winata, E. (2015). Pengaruh Pemberian Kompensasi dan Penilaian Prestasi Kerja terhadap Produktivitas kerja Karyawan pada PT. Askrindo cabang Medan. Jurnal Dunia Ilmu, 1(2).

Yusuf, A. B. (2014). Manajemen Sumer DayaManusia.jakarta: PR. Persada, ED.

Zuhri, \& Pertiwi, L. S. (2016). Airline revenue management under number of no-shows uncertainty. Global Journal of Pure and Applied Mathematics, 12(1), 1003-1012.

Zuhri. (2015). Model Input Output dan Aplikasinya pada Enam Sektor. Jurnal Ilman, $3(1), 16-21$. 